\title{
Deteksi Kualitas Buah Apel Malang Manalagi Menggunakan Algoritma Naive Bayes
}

\author{
Quality Detection Of Malang Manalagi Apple Fruit Using \\ The Algorithm Naive Bayes
}

\author{
Kholiq Prajatama*1, Fajar Eko Nugroho², Andri Faisal Sentosa ${ }^{3}$, Syifa Fauziah ${ }^{4}$, \\ Anggit Dwi Hartanto 5 \\ 1,2,3,4 Program Studi S1 Jurusan Informatika Fakultas Ilmu Komputer Universitas \\ Amikom Yogyakarta Yogyakarta, Indonesia. ${ }^{5}$ Fakultas Ilmu Komputer Universitas \\ Amikom Yogyakarta Yogyakarta, Indonesia \\ E-mail: *11 kholiq.prajatama@students.amikom.ac.id, \\ 2fajar.3775@students.amikom.ac.id, ${ }^{3}$ andri.3788@ students.amikom.ac.id, \\ ${ }^{4}$ syifa.fa@students.amikom.ac.id, ${ }^{5}$ anggit@amikom.ac.id
}

\begin{abstract}
Abstrak
Buah apel merupakan salah satu buah yang banyak dikonsumsi oleh masyarakat, serta vitamin yang terdapat buah apel juga bagus untuk kesehatan. Pada buah apel manalagi yang aslinya dari kota malang, peminatnya bukan hanya kota malang saja tetapi juga dari luar kota bahkan sampai keluar negeri. Dengan banyaknya manfaat yang terdapat di buah apel banyak disukai dikalangan masyarakat. Tetapi terdapat masalah ketika kita memilih buah apel yang segar tetapi kita juga keliru untuk memilih buah apel yang segar tetapi sering kali kita salah pilih buah apel yang kurang segar. Dengan adanya paper ini dapat menambah ilmu akan cara mengklasifikasi buah apel yang segar dan kurang segar atau busuk. Teknologi sekarang dapat mengklasifikasikan buah dengan masing-masing kelas, terdapat algoritma untuk mengklasifikasikan berbagai objek, yaitu algoritma Naive Bayes. Dengan metode yang digunakan di dalam paper ini dapat membantu dalam memilih buah yang segar maupun tidak segar. Dengan tingkat kesegaran yang terdapat pada buah apel dibagi menjadi dua kategori yaitu kategori segar dan busuk. Pada metode ekstrasi fitur peniliti menggunakan intensitas dan data yang digunakan 130 citra. Dengan hasil akurasi $63 \%$.
\end{abstract}

Kata Kunci_-apel malang, naïve bayes, klasifikasi, ekstraksi fitur, citra digital

\begin{abstract}
Apples are one of the fruits that are consumed by many people, and vitamins that contain apples are also good for health. In Manalagi Apple which originated from Malang City, the demand is not only Malang City but also from outside the city and even abroad. With so many benefits found in apples, many are well-liked among the people. But there is a problem when we pick fresh apples but we are also mistaken to choose fresh apples but often we choose the wrong apples that are not fresh. With this paper, you can increase your knowledge on how to classify apples that are fresh and not fresh or rotten. Technology can now classify fruit with each class, there are algorithms for classifying various objects, namely the Naive Bayes algorithm. The method used in this paper can help in choosing fresh or not fresh fruit. With freshness contained in apples divided into two categories, namely the fresh and rotten categories. In the research feature extraction method uses intensity and data used 130 images. With an accuracy of $63 \%$.
\end{abstract}

Keywords: Malang apple, nä̈ve Bayes, classification, feature extraction, digital image.

\section{PENDAHULUAN}

Algoritma klasifikasi citra yang dapat digunakan dua diantaranya adalah Algoritma KNN dan Naïve Bayes[1] [3][4]. Naïve bayes memiliki kesamaan dengan algoritma KNN dalam mengolah jumlah data yang besar akan tetapi Naïve Bayes mengklasifikasikan berdasarkan promentalitas dan teorema 
bayesian yang mengasumsikan tiap-tiap variabel bersifat bebas sedangkan algoritma KNN merupakan sebuah metode proses klasifikasi yang menentukan label (class) dari sebuah objek baru yang berdasarkan mayoritas class dari jarak terdekat kedalam kelompok data latih. Naïve bayes sendiri dapat menangani kuantitatif dan data diskrit, tidak memerlukan data latih dalam jumlah yang banyak untuk mengestimasi pada parameter-parameter yang dibutuhkan untuk proses klasifikasi, dan cepat dalam melakukan kalkulasi[2]. Oleh sebab itu pada penelitian ini diusulkan klasifikasi kesegaran pada buah apel malang berdasarkan ekstraksi fitur citra digital dan Naïve Bayes [5] [6][7]..

Salah satu jenis apel yaitu apel malang, memiliki ciri yang berbeda dari apel-apel lainnya yaitu terdapat pada tingkat pada warna kesegaran buah tersebut. Dimana buah apel malang yang masih belum segar memiliki warna hijau dan untuk buah apel malang yang sudah segar memiliki warna hijau kekuningan. Hal tersebut tentu akan sedikit menyulitkan untuk membedakan antara buah apel malang yang belum segar maupun yang sudah segar apabila tidak terlalu memiliki ilmu mengenai dunia pertanian terutama pada buah apel Sebab orang awam dirasa akan sulit membedakan. Sehingga akan diperoleh penilaian yang berbeda oleh setiap individu yang menyebabkan tingkat akurasi yang berbeda[8][9]. Oleh karena itu dibutuhkan suatu teknologi yang dapat menentukan nilai tingkat akurasi dari pengklasifikasian kesegaran buah apel malang sehingga memperoleh nilai yang konsisten.

Secara umum maka tahapan dalam proses klasifikasi citra digital yaitu akuisisi citra digital, pengolahan citra, ekstraksi ciri/ fitur, pelatihan, pengujian dan pengukuran akurasi citra digital.Tahapan mengekstrak memiliki ciri atau informasi dalam fitur citra digital sangat mempengaruhi untuk mengenali objek yang ada dalam citra tersebut. Semakin banyak ciri yang dilakukan ekstrak akan mempengaruhi tingkat akurasi klasifikasi citra digital. Terdapat bermacam-macam ekstraksi dalam ekstraksi ciri citra yaitu ekstraksi ciri fitur tekstur, bentuk, ukuran, geometri, dan warna[10].

\section{METODOLOGI PENELITIAN}

\subsection{Pengambilan Data}

Pada tahap awal peneliti melakukan pengumpulan data berupa dataset yang kita unduh dari situs www.kaggle.com dengan begitu peneliti lebih mudah untuk mengumpulkan data sehingga peneliti dapat melakukan tahapan berikutnya yaitu pengolahan citra digital.

\subsection{Pra-pengolahan}

Citra buah apel manalagi yang didapatkan pada penelitian ini memiliki resolusi yang cukup besar sehingga dapat meningkatkan kompleksitas perhitungan. Maka perlu dilakukan resize ke dalam ukuran tertentu untuk semua data. Selanjutnya dilakukan proses untuk mentransformasi warna citra dari berwarna (RGB) menjadi keabuan (grayscale), guna inputan untuk proses selanjutnya. Untuk melihat langkah prapengolahan secara lebih detail dapat dilihat pada gambar 1.

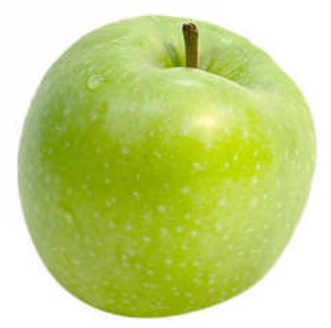

Gambar 1. Buah apel malang manalagi

\subsection{Ekstraksi Fitur}

Ekstraksi fitur citra pada buah apel manalagi bertujuan untuk memperoleh ciri yang terdapat dari citra apel manalagi busuk dan juga segar yang menggunakan ekstraksi fitur histogram yang menampilkan sebuah hasil berupa angka /numerik. Pada penelitian ini menggunakan enam fitur ekstraksi meliputi: rerata intensitas, energi, entropi, deviasi standar, smoothness dan skewness: 


\subsubsection{Fitur Rerata Intensitas}

Fitur ini untuk mendapatkan hasil histogram dan untuk memberikan informasi berupa penyebaran intensitas pada nilai pixel. Rerata intensitas dapat dihitung dengan metode persamaan(1).

$$
M=\sum_{i=0}^{L-1} i \cdot p(i)
$$

\subsubsection{Fitur Energi}

Fitur energi bertujuan untuk mengetahui hasil intensitas piksel terhadap tingkat warna keabuan sehingga dapat menggambarkan nilai yang keseragaman pada sebuah citra. Untuk mendapatkan nilai energi dapat menggunakan persamaan (2).

$$
\text { Energi }=\sum_{i=0}^{L-1}[p(i)]^{2}
$$

\subsubsection{Fitur Entropi}

Fitur ini berguna untuk menampilkan informasi kompleksitas pada citra digital. Semakin tinggi nilai entropi maka juga semakin tinggi pula kompleksitas pada citra tersebut, begitu pula sebaliknya. Untuk mendapatkan fitur energi dapat menggunakan persamaan (3).

$$
\text { Entropi }=\sum_{i=0}^{L-1} p(i) \log _{2}(p(i))
$$

\subsubsection{Fitur Standar Deviasi}

Fitur ini berguna untuk mengetahui tingkat kontras pada citra. Semakin tinggi kontras citra, maka semakin tinggi pula standar deviasinya, begitu pula sebaliknya. Fitur ini dihitung dengan persamaan (4).

$$
\text { Deviasi }=\sqrt{\sum_{i=0}^{L-1}(i-m)^{2} \cdot p(i)}
$$

\subsubsection{Fitur Skewness}

Fitur ini digunakan untuk mengetahui tingkat kesimetrisan citra, atau sering pula disebut momen ordo ketiga. Nilai negatif menunjukan distribusi kecerahan condong kekiri terhadap rerata, sedangkan nilai positif kebalikannya.Nilai fitur ini dihitung dengan persamaan (5).

$$
\text { skew }=\sum_{i=0}^{L-1^{-}}(i-m)^{3} \cdot \mathrm{p}(\mathrm{i})
$$




\subsubsection{Fitur Smoothness}

Fitur ini untuk mengukur tingkat kehalusan sebuah citra. Semakin halus citra maka hasil yang didapatkan nilai R akan semakin tinggi, begitu pula sebaliknya. Nilai ini dihitung dengan persamaan (6).

$$
R=1-\frac{1}{1+\text { Deviasi }^{2}}
$$

\subsection{Tahap Klasifikasi}

Setelah nilai-nilai fitur ekstraksi telah didapat. Nilai tersebut akan diklasifikasi dengan Naive Bayes. Klasifikasi dengan Naive Bayes merupakan klasifikasi berdasar teorema Bayes dengan asumsi antar variabel penjelas independen. Cara ini dapat diasumsikan sebagai keadaan atau ketiadaan dari sebuah kejadian tertentu dari suatu grup yang tidak berhubungan dengan keadaan atau ketiadaan kejadian lain. Teknik ini dapat dipergunakan untuk berbagai masalah klasifikasi dan dapat diterapkan pada klasifikasi buah apel. Dalam hal ini dikhususkan mengenai penggunaan teorema Naive Bayesian untuk klasifikasi apel manalagi. Secara umum untuk metode Naïve Bayes memiliki metode umum pada persamaan (7).

$$
p(C \mid F 1, \ldots, F n)=\frac{p(C) p(F 1, \ldots, F n \mid C)}{p(F 1, \ldots, F n)}
$$

Dimana pencarian probusuklitas X berdasarkan kondisi pada hipotesis Ci pada persamaan (9).

$$
P(X k \mid C i)=g(x i, \mu i, \sigma i)
$$

\subsection{Tahap Evaluasi}

Penelitian ini menggunakan 130 buah apel manalagi yang terdiri dari 65 apel manalagi segar dan 65 apel manalagi busuk. Tujuan penelitian ini untuk membuktikan berapa prosentase keberhasilan pengenalan dengan metode Naïve Bayes dan membandingkan tingkat prosentase keberhasilan yang lebih baik antara algoritma naïve bayes dengan algoritma KNN. Untuk menguji tingkat keberhasilan penulis menggunakan perhitungan akurasi confusion matriks. Untuk menghitung akurasi digunakan persamaan (10).

$$
\text { Accuracy }=\frac{(a+c)}{(a+b+c+d)} \times 100 \%
$$

\section{HASIL DAN PEMBAHASAN}

Penelitian kami ini diimplementasikan dengan menggunakan Software MATLAB, dimana hasil implementasi aplikasi dapat dilihat di gambar 2. 


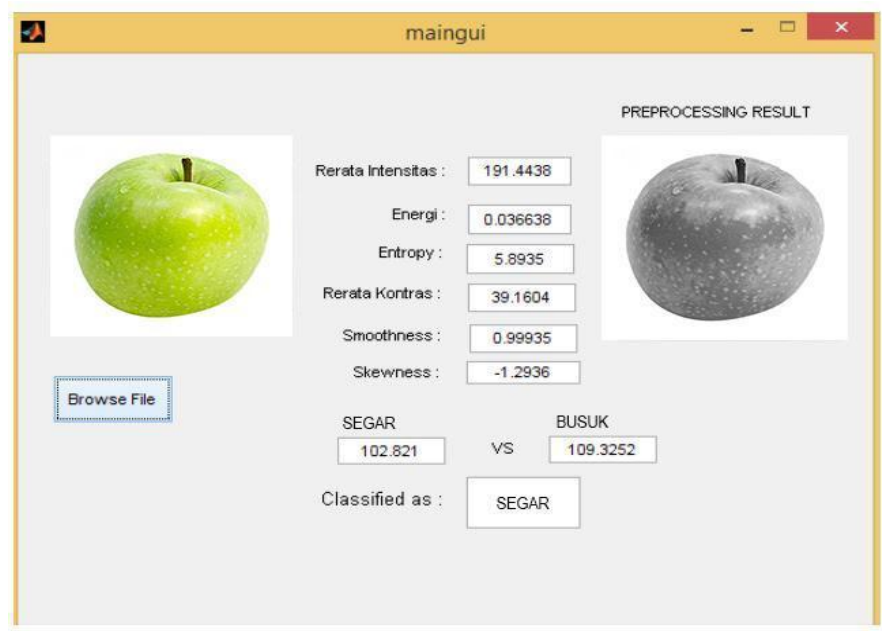

Gambar 2. Aplikasi Deteksi Kualitas Apel Berbasis MATLAB

Berdasarkan gambar 2 dapat dilihat tampilan berbasis Matlab untuk mengklasifikasi tingkat kesegaran buah apel manalagi kedalam kategori busuk atau segar berdasarkan ekstraksi citra menggunakan enam atribut yaitu intensitas, energi, entropi, kontras, smoothness, skewness. Berdasarkan rumus intensitas, energi, entropi, kontras, smoothness dan skewness, didapat nilai-nilai yang disajikan pada tabel 1, tabel 2 dan tabel 3. Tabel 1 berisi data ekstraksi fitur untuk citra training segar, Tabel 2 berisi data ekstraksi fitur pada citra training busuk, dan tabel 3 berisi hasil ekstraksi fitur pada citra testing.

Tabel 1. Data ekstraksi fitur citra training apel manalagi class segar

\begin{tabular}{lllllll}
\hline No & Intensitas & Energi & Entropy & Kontras & Smoothness & Skewness \\
\hline 1. & 173,6006 & 0,02813 & 5,955687 & 38,4285 & 0,999323295 & $-1,08492$ \\
2 & 181,4024 & 0,032456 & 6,076351 & 6,076351 & 6,076351 & $-0,80792$ \\
3 & 173,6006 & 0,02813 & 5,955687 & 38,4285 & 0,999323295 & $-1,08492$ \\
$\cdot$ & $\cdot$ & $\cdot$ & $\cdot$ & $\cdot$ & $\cdot$ &. \\
$\cdot$ & $\cdot$ & $\cdot$ &. & $\cdot$ &. &. \\
50 & 176,8851 & 0,032033 & 6,137699 & 38,17018 & 0,999314111 & $-0,95811$ \\
\hline
\end{tabular}

Tabel 2. Data ekstraksi fitur citra training apel manalagi class busuk

\begin{tabular}{lllllll}
\hline No & Intensitas & Energi & Entropy & Kontras & Smoothness & Skewness \\
\hline 1 & 171,2402 & 0,030987 & 6,198573 & 42,65354 & 0,999450647 & $-0,72855$ \\
2 & 168,9099 & 0,032635 & 6,131053 & 45,28972 & 0,999512708 & $-0,51836$ \\
3 & 183,0888 & 0,03546 & 5,755191 & 38,44792 & 0,999323978 & $-1,39871$ \\
$\cdot$ & $\cdot$ & $\cdot$ & $\cdot$ & $\cdot$ &. &. \\
$\cdot$ & $\cdot$ & $\cdot$ &. &. &. &. \\
50 & 184,0587 & 0,033777 & 5,774477 & 35,11896 & 0,999189851 & $-1,36781$ \\
\hline
\end{tabular}

Tabel 3. Data ekstraksi fitur citra testing apel manalagi

\begin{tabular}{lllllll}
\hline No & Intensitas & Energi & Entropy & Kontras & Smoothness & Skewness \\
\hline 1 & 193,2783 & 0,08269826 & 4,899107718 & 30,21261738 & 0,998905671 & $-39057,68485$ \\
2 & 165,5362 & 0,0268212 & 5,963052418 & 31,09553167 & 0,99896687 & $-38743,08912$ \\
3 & 167,5969 & 0,02684752 & 6,088764456 & 35,37498283 & 0,999201526 & $-42289,88659$ \\
$\cdot$ & $\cdot$ & $\cdot$ & $\cdot$ & $\cdot$ &. &. \\
$\cdot$ &. & $\cdot$ & $\cdot$ & $\cdot$ &. &. \\
30 & 189,1591 & 0,03386218 & 5,876822669 & 41,9861428 & 0,999433054 & $-70234,10144$ \\
\hline
\end{tabular}

Hasil penelitian menggunakan algoritma Naive Bayes tersebut, didapat hasil kecocokan data testing antara data asli citra uji yang diinputkan dan hasil dari algoritma yang diusulkan dengan menggunakan 30 citra uji tersebut. 
Tabel 4. Data ekstraksi fitur citra testing apel manalagi

\begin{tabular}{|c|c|c|c|c|}
\hline No & Nama Citra & Target & Hasil & Keterangan \\
\hline 1 & Apel1.jpg & Segar & Busuk & Salah \\
\hline 2 & Apel2.jpg & Segar & Busuk & Salah \\
\hline 3 & Apel3.jpg & Segar & Segar & Benar \\
\hline 4 & Apel4.jpg & Segar & Busuk & Salah \\
\hline 5 & Apel5.jpg & Segar & Busuk & Salah \\
\hline 6 & Apel6.jpg & Segar & Busuk & Salah \\
\hline 7 & Ape17.jpg & Segar & Segar & Benar \\
\hline 8 & Apel8.jpg & Segar & Segar & Benar \\
\hline 9 & Ape19.jpg & Segar & Segar & Benar \\
\hline 10 & Apel10.jpg & Segar & Segar & Benar \\
\hline 11 & Apel11.jpg & Segar & Segar & Benar \\
\hline 12 & Apel12.jpg & Segar & Segar & Benar \\
\hline 13 & Apel13.jpg & Segar & Segar & Benar \\
\hline 14 & Apel14.jpg & Segar & Segar & Benar \\
\hline 15 & Apel15.jpg & Segar & Segar & Benar \\
\hline 16 & Apel16.jpg & Busuk & Busuk & Benar \\
\hline 17 & Apel17.jpg & Busuk & Busuk & Benar \\
\hline 18 & Apel18.jpg & Busuk & Busuk & Benar \\
\hline 19 & Apel19.jpg & Busuk & Busuk & Benar \\
\hline 20 & Apel20.jpg & Busuk & Busuk & Benar \\
\hline 21 & Apel21.jpg & Busuk & Busuk & Benar \\
\hline 22 & Apel22.jpg & Busuk & Busuk & Benar \\
\hline 23 & Apel23.jpg & Busuk & Segar & Salah \\
\hline 24 & Apel24.jpg & Busuk & Busuk & Benar \\
\hline 25 & Apel25.jpg & Busuk & Busuk & Benar \\
\hline 26 & Apel26.jpg & Busuk & Segar & Salah \\
\hline 27 & Apel27.jpg & Busuk & Segar & Salah \\
\hline 28 & Apel28.jpg & Busuk & Segar & Salah \\
\hline 29 & Apel29.jpg & Busuk & Segar & Salah \\
\hline 30 & Apel30.jpg & Busuk & Busuk & Benar \\
\hline
\end{tabular}

Berdasarkan tabel 4, hasil klasifikasi dari 30 buah apel manalagi terdapat 11 kesalahan deteksi dengan menggunakan metode algoritma Naïve Bayes dan juga dengan menggunakan rumus (10), maka didapat akurasi hanya sebesar $63 \%$. Hasil penelitian ini masih perlu dikembangkan lagi mengingat akurasi yang relatif masih kurang kurang baik.

\section{KESIMPULAN}

Berdasarkan hasil uji coba yang telah dilakukan pada penelitian ini, hasil yang didapatkan adalah dengan metode yang diusulkan dapat digunakan untuk mengklasifikasi apel malang. Hasil akurasinya kurang memuaskan,yaitu 63\%. Maka untuk penelitian selanjutnya bisa dikembangkan lagi.

\section{DAFTAR PUSTAKA}

[1] Bhange, M., \& Hingoliwala, H. A. (2015). Smart Farming: Pomegranate Disease Detection Using Image Processing. Second International Symposium on Computer Vision and the Internet, 280288.

[2] Cempaka, A. R., Santoso, S., \& Tanuwijaya, L. K. (2014). Pengaruh Metode Pengolahan (Juicing And Blending) Terhadap Kandungan Quercetin Berbagai Varietas Apel Lokal dan Impor. Journal of Human Nutrition, 14-22.

[3] Kumari, R., \& Gomothy, V. (2018). Fruit Classification using Statistical Features in SVM Classifier. IEEE, 526-529. 
[4] M.Ayyub, S., \& Manjrankar, A. (2019). Fruit Disease Classification and Identification using Image Processing. IEEE, 754-758.

[5] Manik, F. Y., \& Saragih, K. S. (2017). Klasifikasi Belimbing Menggunakan Naïve Bayes Berdasarkan Fitur Warna RGB. Indonesian Journal of Computing and Cybernetics Systems, 99108.

[6] Panda, S., \& Sethy, P. K. (2017). POST-HARVEST GRADING OF CARICA PAPAYA FRUIT USING IMAGE SEGMENTATION AND SOFT COMPUTING. International Journal of Advanced Research in Computer Science, 192-197.

[7] Ronald, M., \& Evans, M. (2016). CLASSIFICATION OF SELECTED APPLE FRUIT VARIETIES USING NAIVE BAYES. Indian Journal of Computer Science and Engineering, 1319.

[8] Sutopo, T., Tirajani, P. S., Setiadi, D. R., Sari, C. A., \& Rahmawati, E. H. (2017). CBIR for Classification of Cow Types using GLCM and Color Features Extraction. Internasional Conferences on Information Technology, Information Systems and Electrical Engineering (pp. 184-187). Yogyakarta: IEEE.

[9] Yulianto, D., Whidhiasih, R. N., \& Maimunah. (2017). KLASIFIKASI TAHAP KEMATANGAN PISANG AMBON BERDASARKAN WARNA MENGGUNAKAN NAIVE BAYES. Jurnal Penelitian Ilmu Komputer, 60-67.

[10] Zeng, G. (2017). Fruit and Vegetables Classification System Using Image Saliency and Convolutional Neural Network. IEEE, 613-617. 